\title{
Pendampingan Alternatif Investasi Dengan Program Yuk Nabung Saham Pada Masyarakat Desa
}

\author{
Emmy Ermawati \\ Program Studi Akuntansi, STIE Widya Gama Lumajang \\ emmy.ermawati01@gmail.com
}

\begin{abstract}
Abstrak
Kegiatan ini bertujuan untuk memberikan edukasi atau pengetahuan tentang altenatif investasi yang berupa program Yuk Naung Saham. Kabupaten Lumajang mempunyai penduduk yang bervariatif pendapatannya, mulai dari petani, karyawan swasta, pegawai negeri sipil dan pengusaha. Banyak sekali masyarakat beranggapan bahwa investasi itu hanya berupa tabungan di bank dan pembelian asset yang berupa tanah, sawah atau bangunan. Dari pengamatan di lapangan masyarakat lumajang lebih suka berinvestasi dengan membeli ternak. Ada yang berternak ayam dan ketika musim penghujan karena tidak tahan cuaca akhirnya banyak yang mati. Atau berternak sapi yang notabene itu sudah membudaya di Lumajang, tapi ketika sapi tersebut sudah besar resiko hilang juga besar karena terkait dengan keamanan di desa. Tidak jauh beda dengan membeli tanah/sawah, karena masyarakat kurang paham dengan legalitas hukum maka tidak sedikit yang tertipu atas pembelian asset tersebut. Oleh karena itu pentingnya berinvestasi dalam bentuk saham sangat berperan aktif tidak hanya pada kebutuhan ekonomi investor tetapi memberikan sumbangan yang besar terhadap pendapatan negara dari sisi investasi. Manfaat dari investasi saham sendiri antara lain yaitu dapat meningkatkan asset dari deviden yang dimiliki. Menghindari jeratan hutang disaat waktu tertentu kita membutuhkan keuangan secara mendadak. Bisa menjadikan hidup lebih hemat dengan menentukan sekala prioritas kebutuhan. Dan lebih efektifnya yaitu dengan berinvestasi saham kita lebih menyiapkan untuk kebutuhan dimasa yang akan datang.
\end{abstract}

\section{Kata Kunci : investasi, alternatif investasi, investasi saham}

\begin{abstract}
Abstrack
This activity aims to provide education or knowledge about alternative investments in the form of Yuk Shares Savings program. Lumajang Regency has a population with varying income, starting from farmers, private employees, civil servants and entrepreneurs. Many people assume that the investment is only in the form of savings in the bank and the purchase of assets in the form of land, rice fields or buildings. From observations in the field, Lumajang people prefer to invest by buying livestock. There are those who raise chickens and when the rainy season because they cannot stand the weather, many people die. Or raising cattle which incidentally has been cultivated in Lumajang, but when the cow is large the risk of loss is also large because it is related to security in the village. It is not much different from buying land / rice fields, because people are not familiar with the legality of the law, not a few are fooled into buying these assets. Therefore, the importance of investing in stocks is very active not only in the economic needs of investors but also contributes greatly to state income from the investment side. The benefits of own share investment include, among other things, increasing assets from dividends owned. Avoiding debt bondage at certain times we need financially suddenly. Can make life more efficient by determining the scale of priority needs. And more effective is by investing in stocks, we are better prepared for future needs.
\end{abstract}




\section{Keywords: investment; alternative investment; stock investment}

\section{PENDAHULUAN}

Secara umum, pengertian dari investasi adalah penanaman aset atau dana yang dilakukan oleh sebuah perusahaan atau perorangan untuk jangka waktu tertentu demi memperoleh imbal balik yang lebih besar di masa depan. Ada banyak hal yang terlibat dalam aktivitas ini, dan beberapa di antaranya adalah jumlah dana dan tujuan dari investasi itu sendiri. Bagi yang sudah lama melibatkan diri dalam dunia penanaman modal, baik lokal maupun internasional, istilah 'berinvestasi' bukanlah sesuatu yang asing. Namun bagi pemula, penjelasan singkat dan jelas mengenai pengertian dasar dan cara berinvestasi sangatlah dibutuhkan. Berikut adalah penjabaran sederhana untuk Anda yang tertarik dan masih baru dalam aktivitas ini.

Apa itu diversivikasi, untuk memperoleh hasil yang diharapkan, berbagai strategi penanaman modal memang sebaiknya dilakukan. Salah satu strategi yang paling sering dilakukan adalah dengan sistem diversifikasi atau menyebar modal yang dimiliki ke beberapa jenis investasi. Diversifikasi juga bisa diterapkan ke dalam satu jenis investasi. Misalnya, si investor memilih investasi saham, dan dia menyebarnya tidak hanya pada satu perusahaan saja melainkan lebih. Hal ini bertujuan untuk memperkecil risiko kerugian pada return nanti. Atau bisa dibilang, jika salah satu perusahaan bangkrut, maka posisi investor masih relatif aman dengan adanya saham pada perusahaan lainnya.

Saat dan jangka waktu yang kita pilih haruslah tepat. Poin terakhir ini tampak sederhana namun memiliki pengaruh yang besar. Apa pun jenis investasi Anda, waktu memengaruhi perkembangan uang. Pada dasarnya, ketika berinvestasi, Anda tentu harus menetapkan jangka waktu tertentu. Untuk jenis obligasi misalnya, Anda bisa mengambil jangka waktu selama 5 tahun. Lalu, apa hubungannya dengan saat yang tepat untuk memulai investasi? Dengan jangka waktu investasi yang ada, semakin dini Anda memulai, maka semakin cepat pula Anda 'memanennya'. Jadi, jika dalam empat tahun ke depan, salah satu anggota keluarga harus masuk ke universitas, maka berinvestasi dari sekarang adalah pilihan bijak. Dan jika bermasalah pada modal yang minim, Anda bisa mulai mencari tipe dan tempat berinvestasi yang tidak memerlukan dana besar. Atau, jika ingin memperoleh pengetahuan yang lebih mendetail, Anda bisa menggunakan penasihat khusus. Untuk jasa seperti ini, Anda tentu harus menyiapkan dana tersendiri. Alternatif berinvestasi yang mudah bisa dengan memberikan pinjaman melalui platform peer-to-peer lending Akseleran. Bisa mulai investasi dengan Rp. 100,000 saja, dan prosesnya online. Permasalahan yang selalu muncul dalam berinvestasi: a) Apakah yang dimaksud dengan investasi, b)Apakah Tujuan dan manfaat dari investasi, c) Jenis investasi yang beraneka ragam, d) Apakah saham bisa menjadi alternatif investasi. Luaran dalam kegiatan masyarakat ini berupa : masyarakat mengerti akan arti dari investasi, macam-macam investasi dan cara berinvestasi saham yang tepat dan aman.

\section{METODE PELAKSANAAN}

Berikut alur pelaksaaan kegiatan pengabdian masyarakat yang dilakukan di beberapa desa yang berkaitan dengan program Investasi Yuk Nabung Saham..

Tabel 3.1

Alur Pelaksanaan Kegiatan Pengabdian Masyarakat 


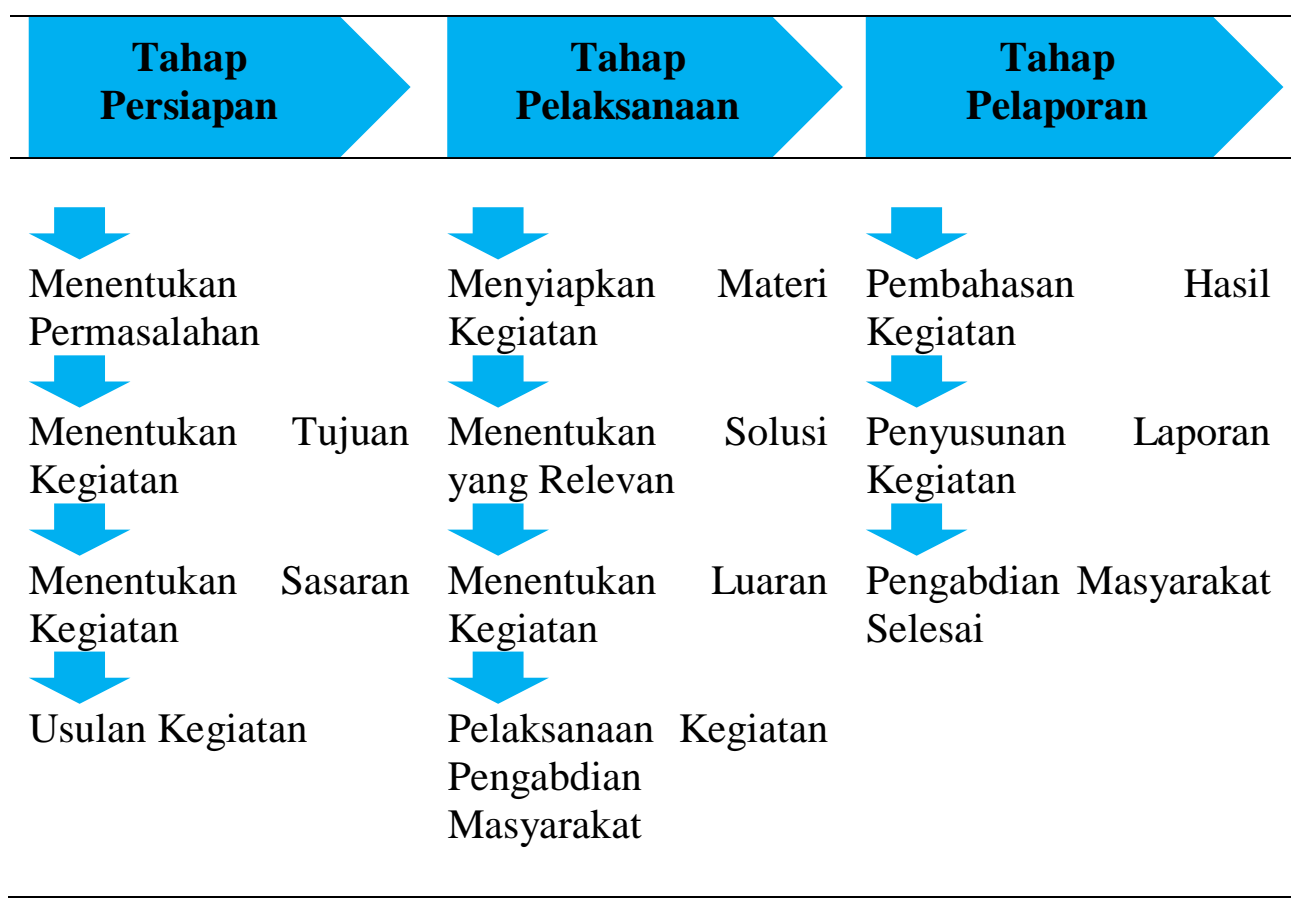

Keterangan dari alur di atas adalah sebagai berikut:

Tahap persiapan, merupakan tahapan dengan tujuan mempersiapkan kegaitan agar mencapai tujuan yang telah dibuat sebelumnya. Sistematis dari tahap ini telah diberikan pada Tabel 4.1 dimana semua tahapan saling terkait dan diakhiri dengan penyusunan proposal atau usulan kegaiatan.

Tahap pelaksanaan, merupakan tahapan inti dari kegiatan pengabdian masyarakt ini. Pada tahapan ini berisi penyampaian materi yang relevan kepada sasaran kegiatan guna penyelesaian permasalahan yang diangkat.

Tahap pelaporan, merupakan tahapan akhir dari kegiatan ini dimana disusunnya laporan kegiatan yang selanjutnya dapat digunakan atau dimanfaatkan oleh orang lain

\section{HASIL dan PEMBAHASAN}

PT Bursa Efek Indonesia (BEI) bekerja sama dengan Kustodian Sentral efek Indonesia menyelenggarakan program investasi Yuk Nabung Saham. Dimana investasi ini juga diawasi oleh OJK yaitu Otoritas Jasa Keuangan yang memberikan rasa nyaman bagi masyarakat atas kenyamanan investasi ini. Ada juga sisi lain dalam pendapat masyarakat bahwa "Sahamnya itu seperti Judi, bagi sebagian orang belum memahaminya. Kurangnya edukasi yang cukup atas saham banyak yang salah kaprah tentang pemahaman saham oleh masyarakat. Sebagian masyarakat masih cenderung lebih nyaman berinvestasi secara konvensional yaitu dengan menyimpan uang di celengan, bank atau lembaga keuangan yang lain.

Menyongsong era globalisasi tentunya memerlukan banyak persiapan. Terkadang segelintir orang bingung untuk mengalokasikan asset yang dimilikinya. Islam memerintahkan agar harta dapat terdistribusi dan bisa digulirkan itu artinya kekayaan yang kita miliki harus benar-benar dimanfaatkan dengan sebaik-baiknya. Salah satu cara agar kita dapat memetik nilai ekonomis dari asset yang kita miliki yaitu menginvestasikannya. Ada satu hal yang harus kita ingat jangan sampai salah pilih dalam menginvestasikan harta yang kita miliki, artinya investor dituntut untuk paham bagaimana dana yang diinvestasikan itu nantinya akan digulirkan atau dialokasikan. 
Sebagai investor sebelum menginvestasikan asset alangkah lebih baiknya untuk melakukan pertimbangan seperti halnya pertimbangan mengenai finansial, yaitu mempertimbangkan imbal hasil (return) dan risiko (risk) dari kegiatan investasinya. Akan tetapi ada pula investor yang dalam kegiatan investasinya tidak semata-mata mempertimbangkan aspek finansial namun juga mempertimbangkan nilai-nilai yang dianutnya seperti ajaran agama. Investor yang demikian akan menolak berinvestasi pada perusahaan yang menghasilkan produk atau aktivitas bisnis yang bertentangan dengan prinsip agama.

Di Indonesia yang mayoritas penduduknya beragama Islam mulai dikembangkan investasi berbasis syariah, dimana investasi tersebut mengintegrasikan nilai-nilai agama yang dianut dalam kegiatan investasi dengan cara melakukan proses seleksi (screening) dalam memilih instrumen-instrumen investasinya. Salah satu sarana dalam berinvestasi sesuai prinsip Islam adalah melalui pasar modal syariah. Kemunculan pasar modal syariah pertama kali di Indonesia ditandai dengan diluncurkannya Danareksa Syariah oleh Danareksa Investment Management pada Juli 1997. Danareksa syariah merupakan reksadana saham yang pertama kali secara eksplisit menyatakan investasinya bersifat syariah. Pada akhir tahun 2000, PT Bursa Efek Jakarta bekerja-sama dengan Danareksa Management Indonesia mengeluarkan Jakarta Islamic Index (JII) yang merupakan indeks dari 30 saham paling likuid dan memenuhi kriteria syariah sesuai ketentuan Dewan Syariah Nasional (DSN). Sedangkan Indeks Saham Syariah Indonesia (ISSI) yang menggambarkan kinerja seluruh saham syariah di Indonesia baru diluncurkan pada 12 Mei 2011. Indonesia dinyatakan secara resmi memiliki Pasar Modal Syariah pada tanggal 14 Maret 2003, dimana saham-saham yang diperdagangkan adalah saham-saham yang telah melalui proses screening sesuai dengan kriteria syariah dengan batasan maksimal hutang ribawi $45 \%$ dari modal.

Namun yang terjadi saat ini, pemahaman masyarakat tentang pasar modal syari'ah selama ini selalu identik dengan spekulasi, bahkan ada yang mengasosiasikan sebagai judi. Kesalahpahaman tersebut terjadi sebagai akibat dari kurang pahamnya mereka tentang investasi di pasar modal. Selain itu, banyaknya pelaku pasar yang melakukan transaksi tanpa perhitungan dan dasar analisa, sehingga menambah kesalahpahaman masyarakat tentang pasar modal. Maka untuk mengentaskan semua permasalahan yang terjadi BEI dan BapepamLK bekerjasama dengan DSN-MUI aktif memberikan pemahaman kepada masyarakat tentang Pasar Modal Syariah. Keterlibatan DSN-MUI dalam mengedukasi masyarakat tentang Pasar Modal Syariah dapat meningkatkan kepercayaan dan keyakinan masyarakat untuk melakukan investasi di Pasar Modal Syariah.

Jadi dari permasalahan diatas dapat kita memberikan edukasi dan wawasan yang luas dengan apa yang dimaksud investasi. Setelah paham arti dan manfaat investasi barulah kita memberkan alternatif investasi apa saja yang ter kini untuk masyarakat. Ternyata tidak semua orang melek investasi dan ini dibuktikan dengan masih banyaknya masyarakat yang takut untuk berinvestasi. Mereka rata-rata takut uang yang mereka tabung atau investasikan akan hilang. Dengan adanya program Yuk Nabung saham maka masyarakat akan merasa aman dan nyaman dalam berinvestasi saham. 


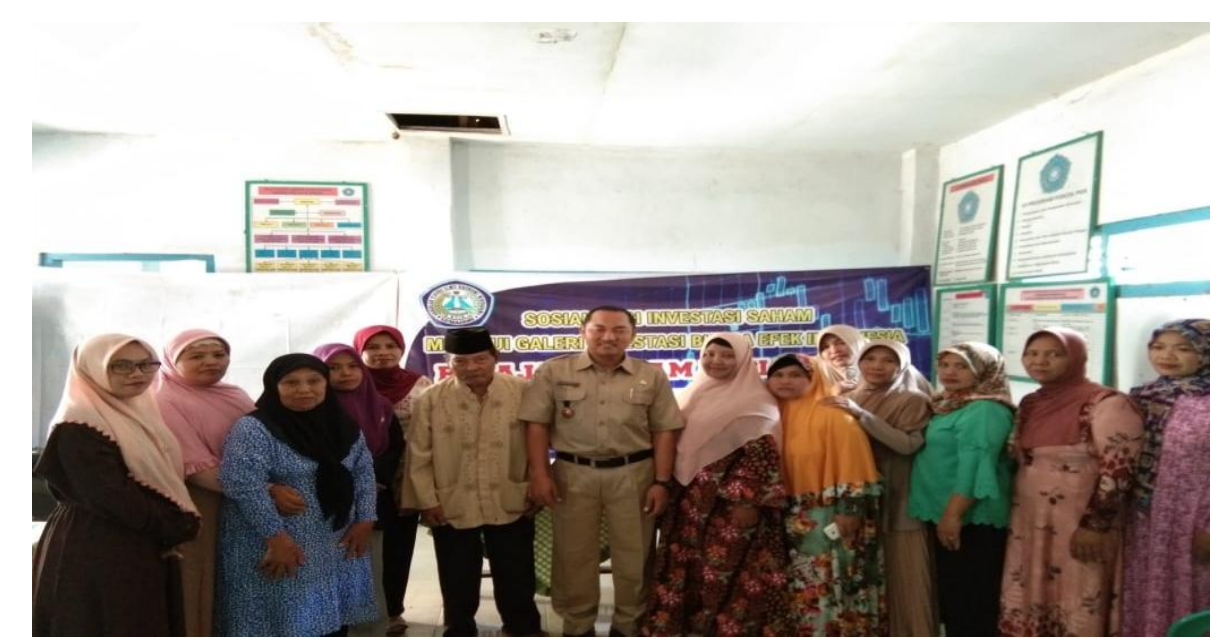

Gambar 1.1 Sosialisasi Yuk Nabung Saham di desa Bondoyudo

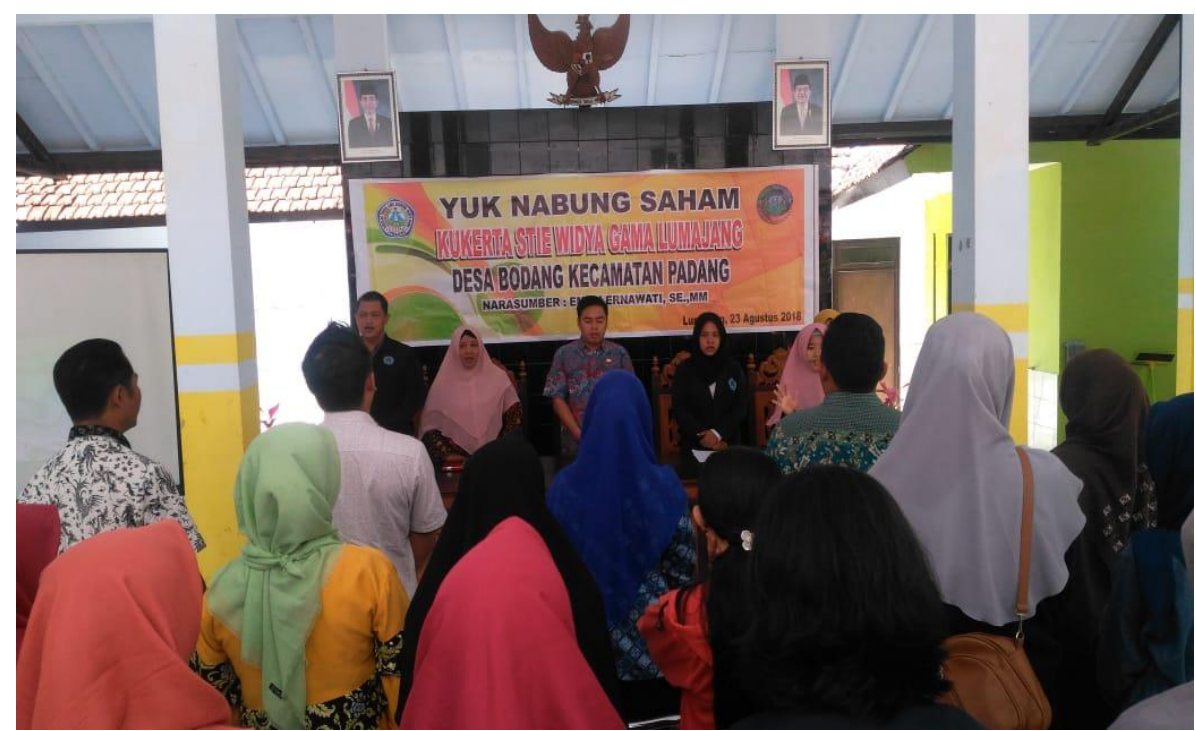

Gambar 1. 2 Sosialisasi Yuk Nabung Saham di desa Bodang

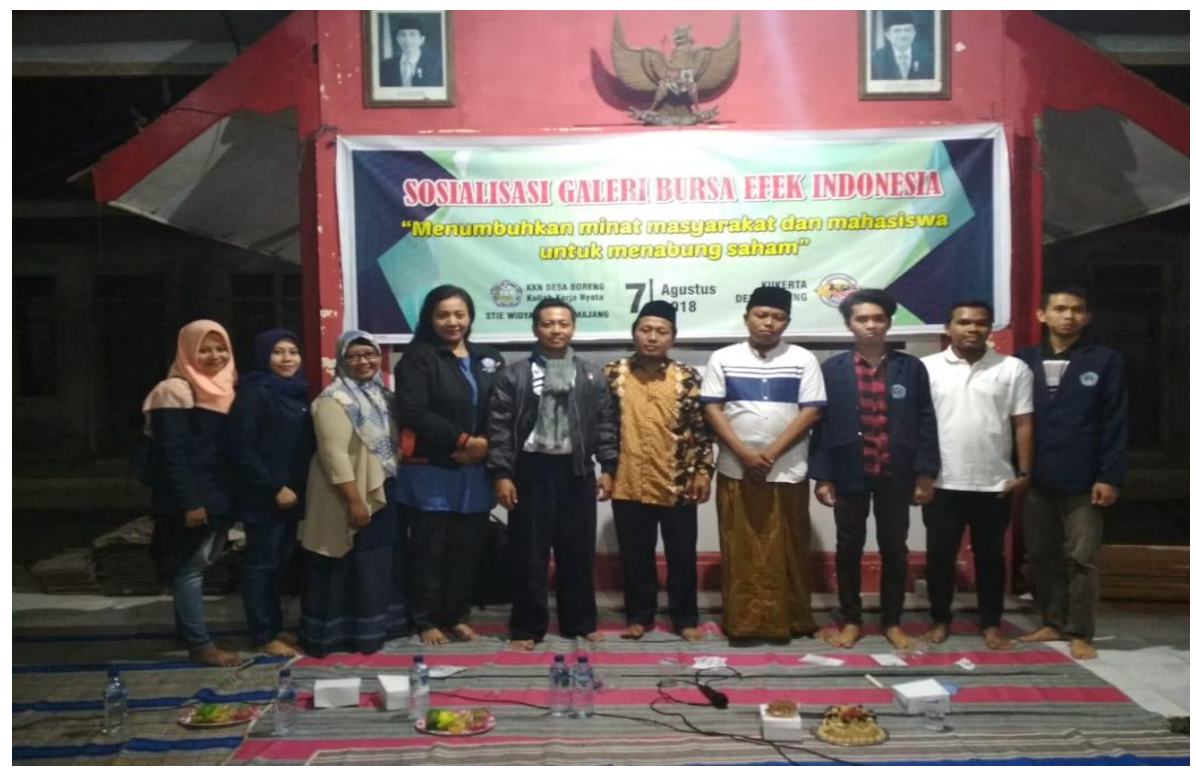

Gambar 1. 3 Sosialisasi Yuk Nabung Saham di desa Boreng 


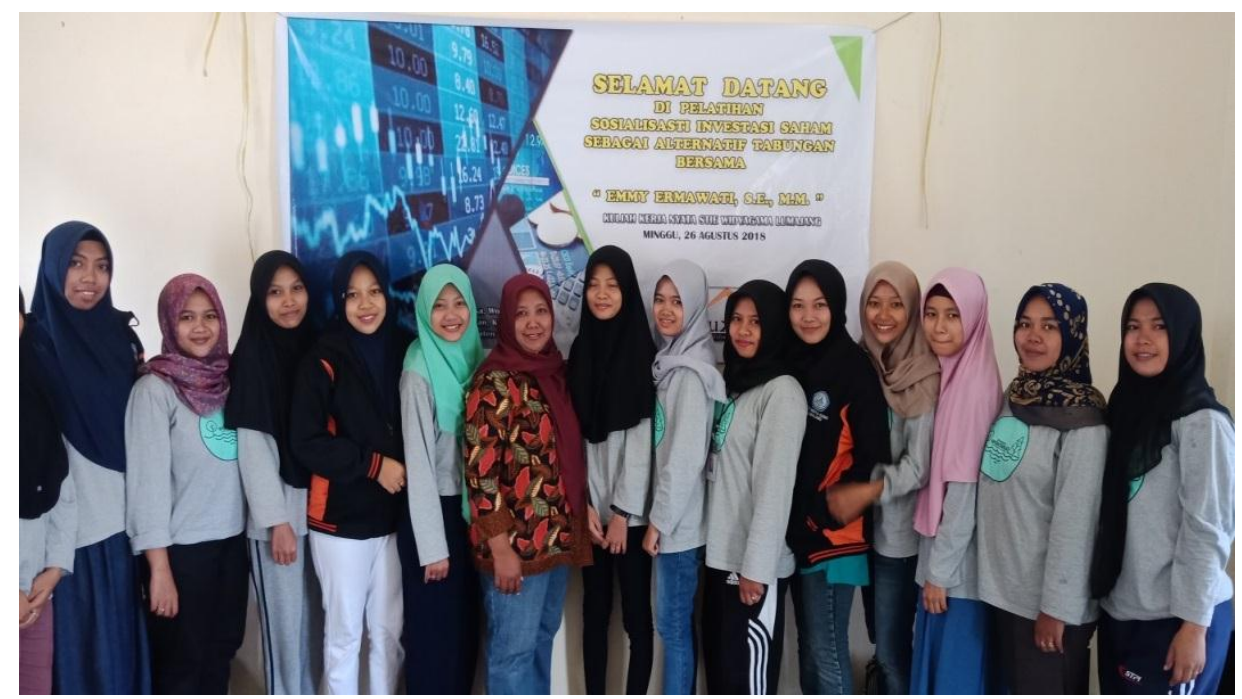

Gambar 1. 4 Sosialisasi Yuk Nabung Saham di desa Wonorejo

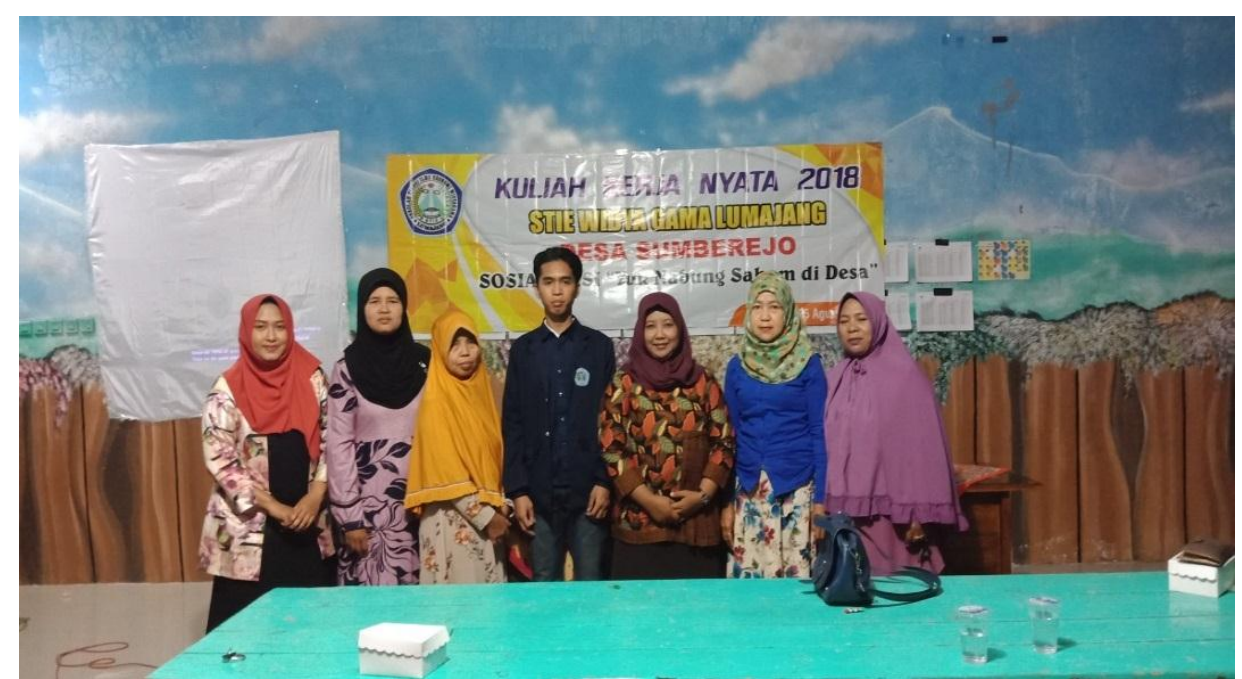

Gambar 1.5 Sosialisasi Yuk Nabung Saham di desa Sumberejo

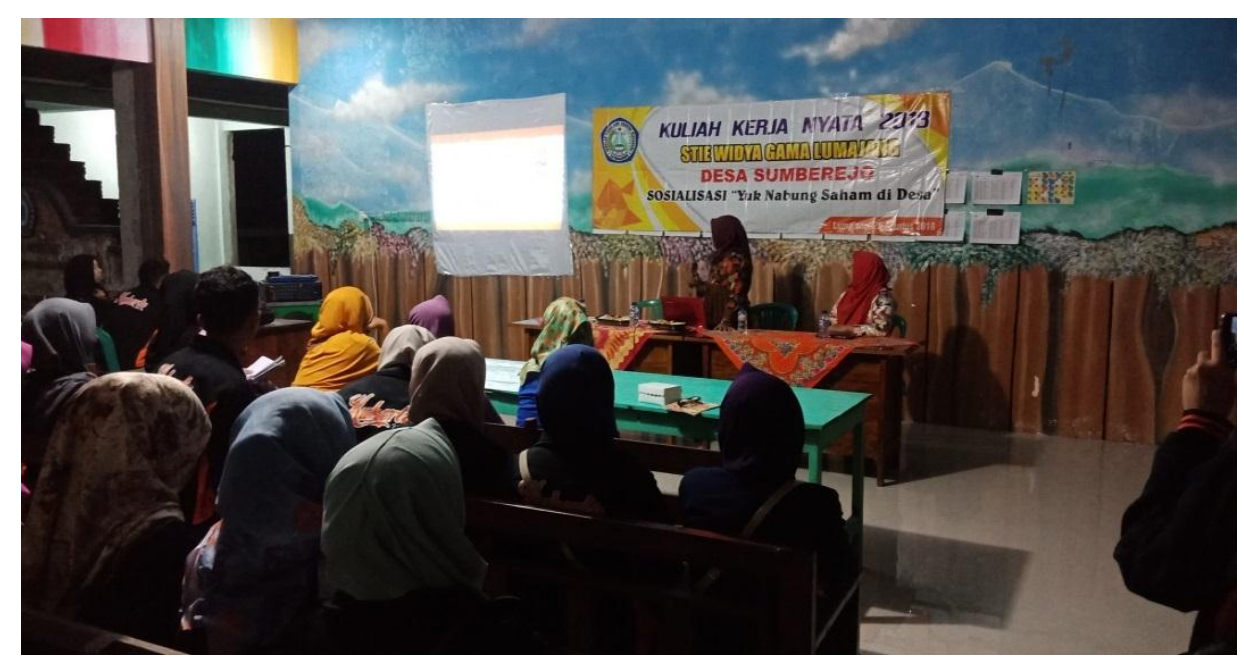

Gambar 1. 6 Sosialisasi Yuk Nabung Saham di desa Sumberejo

\section{KESIMPULAN}


1. Pengertian dari investasi

Yang dimaksud dengan investasi adalah suatu tindakan menanamkan sumber daya atau modal pada saat ini, dengan harapan bisa mendapatkan manfaat yang lebih di masa yang akan datang. Atau definisi investasi yaitu suatu tindakan menanamkan dana saat ini atau sekarang, dengan harapan dapat menghasilkan dana yang lebih besar dari dana yang di tanamkan saat awal melakukan investasi.

2. Tujuan dan manfaat dari investasi

Tujuan investasi

a. Mendapatkan penghasilan yang tetap dalam setiap periode. Misalnya seperti bunga, royalti, uang sewa, dan lain-lain yang dimana penghasilannya dapat digunakan untuk kebutuhan hidup.

b. Mendapatkan dana khusus, misalnya dana tersebut digunakan untuk keperluan sosial, memperluas usaha dan lain-lain.

c. Menjamin tersedianya bahan baku dan memperoleh pasar untuk menjual produk yang telah di produksi.

d. Mengontrol perusahaan, dengan cara melalui kepemilikan aset-aset perusahaan tersebut.

e. Mengurangi persaingan diantara perusahaan-perusahaan yang bergerak di bidang yang sama.

f. Menjaga hubungan baik antara perusahaan maupun cabang perusahaan.

3. Manfaat Investasi

Adapun beberapa manfaat yang bisa di dapatkan dalam berinvestasi, misalnya seperti:

a. Dapat meningkatkan aset

b. Dapat memenuhi kebutuhan hidup di masa depan

c. Hidup jadi lebih hemat

d. Menciptakan kebahagiaan bagi keluarga

4. Jenis-Jenis Investasi

Adapun Beberapa Investasi finansial misalnya seperti:

a. Deposito

b. Saham

c. Obligasi

d. Reksa dana

e. Menabung

Pentingnya sosialisasi dan menerima informasi berperan aktif dalam kehidupan masyarakat. Mau menerima perubahan yang terkini merupakan salah satu keputusan dan berinvestasi. Disisi lain kita tidak hanya berinvestasi tetapi juga memperoleh keuntungan selain dari pekerjaan pokok kita.

Mahasiswa sebagai kaum yang berpendidikan dan telah mempelajari banyak dalam saham hendaknya bisa mengambil sisi positif dalam investasi ini. Untuk mencukupi diri sendiri dan biaya kuliah. Tidak menutup informasi yang terkini seputar saham serta tetap mempelajari tren dan teknik membaca grafik terbaru dalam berinvestasi akan sangat berpengaruh dalam memerdekakan financial.

\section{DAFTAR PUSTAKA}

Sumber: http://www.dakwatuna.com/2016/11/25/83813/perspektif-masyarakat-terhadapinvestasi-syariah/\#ixzz5QIbOpAfK

Follow us: @ dakwatuna on Twitter |dakwatunacom on Facebook 